\author{
Jasper Florie \\ Rogier E. van Gelder \\ Michiel P. Schutter \\ Adrienne van Randen \\ Henk W. Venema \\ Steven de Jager \\ Victor P. M. van der Hulst \\ Anna Prent \\ Shandra Bipat \\ Patrick M. M. Bossuyt \\ Lubbertus C. Baak \\ Jaap Stoker
}

\section{Feasibility study of computed tomography colonography using limited bowel preparation at normal and low-dose levels study}

Received: 27 July 2006

Revised: 17 March 2007

Accepted: 17 April 2007

Published online: 5 June 2007

(C) Springer-Verlag 2007

J. Florie $(\bowtie) \cdot$ R. E. van Gelder ·

M. P. Schutter - A. van Randen .

S. de Jager - A. Prent - S. Bipat

Department of Radiology,

Academic Medical Center,

G1-230,

P.O. Box 22660, 1100 DD

Amsterdam, The Netherlands

e-mail: J.Florie@amc.uva.nl

Tel.: +31-20-5662432

Fax: +31-20-5669119

\section{H. W. Venema}

Department of MedicaPhysics, Academic Medical Center,

L0-106,

P.O. Box 22660, 1100 DD

Amsterdam, The Netherlands

V. P. M. van der Hulst

Department of Radiology,

Onze Lieve Vrouwe Gasthuis,

P.O. BOX 95500, 1090 HM

Amsterdam, The Netherlands

P. M. M. Bossuyt

Department Clinical Epidemiology

\& Biostatistics,

Academic Medical Center,

J1b-212,

P.O. BOX 22660, 1100 DD

Amsterdam, The Netherlands

\author{
L. C. Baak \\ Department Gastroenterology, \\ Onze Lieve Vrouwe Gasthuis, \\ P.O. BOX 95500, $1090 \mathrm{HM}$ \\ Amsterdam, The Netherlands \\ J. Stoker \\ Department of Radiology, \\ Academic Medical Center, \\ G1-211, \\ P.O. BOX 22660, 1100 DD \\ Amsterdam, The Netherlands
}

\begin{abstract}
The purpose was to evaluate low-dose CT colonography without cathartic cleansing in terms of image quality, polyp visualization and patient acceptance. Sixty-one patients scheduled for colonoscopy started a low-fiber diet, lactulose and amidotrizoic-acid for fecal tagging 2 days prior to the CT scan (standard dose, 5.8-8.2 $\mathrm{mSv}$ ). The original raw data of 51 patients were modified and reconstructed at simulated 2.3 and $0.7 \mathrm{mSv}$ levels. Two observers evaluated the standard dose scan regarding image quality and polyps. A third evaluated the presence of polyps at all three mSv levels in a blinded prospective way. All observers were blinded to the reference standard: colonoscopy. At three times patients were given questionnaires relating to
\end{abstract}

their experiences and preference. Image quality was sufficient in all patients, but significantly lower in the cecum, sigmoid and rectum. The two observers correctly identified respectively $10 / 15$ $(67 \%)$ and $9 / 15(60 \%)$ polyps $\geq 10 \mathrm{~mm}$, with 5 and 8 false-positive lesions (standard dose scan). Dose reduction down to $0.7 \mathrm{mSv}$ was not associated with significant changes in diagnostic value (polyps $\geq 10 \mathrm{~mm}$ ). Eighty percent of patients preferred CT colonography and $13 \%$ preferred colonoscopy $(\mathrm{P}<0.001)$. CT colonography without cleansing is preferred to colonoscopy and shows sufficient image quality and moderate sensitivity, without impaired diagnostic value at dose-levels as low as $0.7 \mathrm{mSv}$.

Keywords CT colonography · Fecal tagging - Colonic neoplasm · Colonoscopy
Abbreviations CTC: computed tomography colonography . $\mathrm{CC}$ : conventional colonoscopy

\section{Introduction}

Since computed tomography colonography (CTC) has shown good results in detecting clinically relevant polyps [1-6], studies have been performed focusing on increasing patient acceptance by reducing the bowel preparation. This can be done by adding an oral contrast agent to meals (fecal tagging) [7-12] in combination with a low-fiber diet, and sometimes lactulose for stool softening, thereby obviating extensive cleansing. 
Different studies have been performed using barium, iodine or a combination of both as tagging material. However, only a limited number of these studies on CTC have used limited bowel preparation. Few have evaluated the diagnostic value and patient acceptance of CTC. In parallel with the development of limited bowel preparation strategies, (ultra) low-dose protocols have been evaluated [13-15].

To our knowledge, to date no studies have evaluated the effect of dose reduction on sensitivity and specificity in patients with a limited bowel preparation. Only one study [7] has evaluated limited bowel preparation at a relatively low dose level (140 kVp, $10 \mathrm{mAs})$. This study has shown very good results; however, these data have not been reproduced yet. Moreover, as only one dose-level was studied, the effect of dose reduction remains unknown.

The purpose of this study was to evaluate limited bowelpreparation CTC using an oral contrast agent (amidotrizoic acid) in terms of image quality, patient acceptance and polyp visualization using conventional colonoscopy (CC) as a reference standard. A second objective was to determine the effect of substantially reducing the radiation dose levels on the diagnostic accuracy of limited bowel preparation CTC, again using $\mathrm{CC}$ as the reference standard.

\section{Materials and methods}

\section{Study population}

Patients of the Onze Lieve Vrouwe Gasthuis at increased risk for colorectal cancer (personal or family history of colorectal polyps or cancer) [16] who were scheduled to undergo CC between April 2002 and August 2003 were invited to participate in the study. Exclusion criteria were: impossibility to understand the information/informed consent, age below 18 years, pregnancy and inflammatory bowel disease. The study was approved by the institutional review board of the Onze Lieve Vrouwe Gasthuis and Academic Medical Center. All patients gave written informed consent.

\section{CTC bowel preparation and scanning protocol}

Four weeks prior to the $\mathrm{CC}$ patients were asked to ingest amidotrizoic acid $(20 \mathrm{mg} / \mathrm{ml}$, made by the hospital pharmacy, $11.7 \mathrm{mg} \mathrm{I} / \mathrm{ml}$; corresponding to approximately 30 times diluted Gastrografin $370^{\circledR}$ ) three times a day (100 $\mathrm{ml}$ at breakfast and lunch, $300 \mathrm{ml}$ at dinner) with a low-fiber diet (well cooked vegetables and meat, no fibrous fruit, no whole-wheat products, no nuts) starting 2 days prior to CTC. Lactulose (12 g, lactulose CF powder $6 \mathrm{~g} / \mathrm{sachet}$, Centrafarm, Etten-Leur, The Netherlands) was taken in the morning for 3 days prior to CTC for stool softening. Twenty $\mathrm{mg}$ of butylscopolaminebromide (Buscopan; BoehringerIngelheim, Ingelheim, Germany), when contraindicated,
$1 \mathrm{mg}$ of glucagon hydrochloride (Glucagen; Novo-Nordisk, Bagsvaerd, Denmark) was administered intravenously. The colon was insufflated with a $\mathrm{CO}_{2}$-air mixture $(13.2 \%$ vol.) using a flexible catheter until patients experienced discomfort $( \pm 2-31)$. Patients were scanned in prone and supine position with a four-slice MX8000 (Philips Medical Systems, Best, The Netherlands) CT scanner $(120 \mathrm{kV}$, rotation time $0.75 \mathrm{~s}$, pitch 1.25 , collimation $4 * 2.5 \mathrm{~mm}$, section thickness $3.2 \mathrm{~mm}$, and reconstruction interval $1.6 \mathrm{~mm}, 50$ or 70 milliampere-second (mAs); $70 \mathrm{mAs}$ if the abdominal circumference was $>102.5 \mathrm{~cm}$, scan time $20-25 \mathrm{~s}$ ).

\section{Colonoscopy}

Prior to CC, each patient was instructed to ingest 41 of a macrogol solution (Colofort macrogol 4000 sachets, Ipsen, Hoofddorp, The Netherlands), starting on the evening prior to the $\mathrm{CC}$. CC was performed by one of three experienced gastroenterologists of the Onze Lieve Vrouwe Gasthuis (experience as gastroenterologist: 23, 12 and 4 years) and recorded on videotape. Patients received sedatives [5 $\mathrm{mg}$ midazolam (Dormicum; Roche, Basel, Switzerland)] and analgesics [0.05 mg fentanyl (Janssen Pharmaceuticals, Beerse, Belgium)] at the request of the patient. If polyps were present, the location was determined and size was estimated, based on comparison with an open biopsy forceps prior to removal. A polyp was considered flat if its height was less than one-half of the diameter of the lesion [17]. Only segments visualized at $\mathrm{CC}$ were used for analysis.

\section{Simulation of low-dose CT colonography}

To study polyp detection at lower dose, CTC examinations were simulated with a lower dose/mAs-value using an established simulation technique $[18,19]$ that has been applied in two earlier CTC studies [13, 14]. This simulation method consists of the controlled increase of noise in the raw $\mathrm{CT}$ transmission data prior to reconstruction of the images. In this way, scans were simulated at $20 \mathrm{mAs}$ (in the order of $2.3 \mathrm{mSv}$ for two scans: supine and prone) and $6 \mathrm{mAs}$ $( \pm 0.7 \mathrm{mSv})$. A previous simulation study has demonstrated that the radiation dose of CTC after extensive bowel cleansing can be reduced down to $0.2 \mathrm{mSv}$ [13]. Since the contrast between tissue and tagged fecal material in limited bowel preparation colons is lower than that between air and tissue, we chose $0.7 \mathrm{mSv}$ as the lowest simulated dose-level next to $2.3 \mathrm{mSv}$.

\section{CTC evaluation}

An unblinded research fellow (J.F., experience: evaluated 300 CTC) matched findings at CC (polyps $\geq 6 \mathrm{~mm}$ and colorectal cancer) with the CTC data to provide a frame of 
reference for true positive findings at CTC. Only exact matches in shape, size and location were scored as a positive match. All images were then independently evaluated using a primary $2 \mathrm{D}$ display mode by three blinded observers. The first observer (research fellow, R.v. G., experience: compared $>300$ CTCs with CC videos) evaluated the original CTC scan for image quality and for polyps. Scores were assigned (per patient/segment, Table 1) for overall image quality, luminal distension, homogeneity and presence of stool. The second observer evaluated the original CTC for polyps and marked those examinations that were not diagnostic. If both observers rated a CTC as not diagnostic, this patient was excluded from analysis. The third observer first evaluated the simulated $0.7 \mathrm{mSv}$ scans for presence of polyps at least 4 weeks after the simulated $2.3 \mathrm{mSv}$ scans, and again at least 4 weeks later the original CTC scans. All lesions were measured and screenshots were taken. The second observer (V.v.d.H., experience: 8 years of clinical CT experience as abdominal radiologist) and the third observer (A.v.R., a research fellow in radiology with no prior experience with CTC) had had a learning curve in evaluating $50 \mathrm{CTCs}$ with CC feedback.

Polyp detection and image quality

A polyp detected at CTC was labeled as true positive if three criteria were met: segmental location and location within the segment corresponded with CC (when situated near the borders of the segment, localization in the adjacent segment was also accepted), the polyp size as estimated by the endoscopist (open forceps) corresponded with size as measured on CTC $(50 \%$ margin based on the CC size was allowed), and appearance (morphology) closely resembled that of the corresponding polyp at videotaped CC. The unblinded research fellow determined the nature of falsepositive findings $\geq 10 \mathrm{~mm}$ by reviewing the videotaped $\mathrm{CC}$ and CTC. If the polyp was possibly missed at CC, a repeat $\mathrm{CC}$ was called for.

\section{Patient questionnaires}

Patient experience and preference were evaluated by six questionnaires (scales are shown in Table 1): 2 weeks prior to the CTC, directly after the CTC bowel preparation, after the CTC, after the CC preparation, after the $\mathrm{CC}$ and 5 weeks later. The first and the last questionnaires were sent by mail. After the CTC bowel preparation, patients were asked how burdensome they rated the CTC bowel preparation, and the most burdensome aspect. After CTC they rated how much pain they had experienced and how burdensome the CTC had been. Prior to CC patients were asked how burdensome the extensive bowel preparation had been. After the $\mathrm{CC}$ they were asked how much pain they had experienced and how burdensome the CC had been. After the CC and 5 weeks later, patients were asked for their preference for either CTC or CC assuming that both techniques were equally accurate, while in $20 \%$ of CTC examinations clinically relevant lesions would be shown, necessitating a therapeutic CC. Two weeks prior to the CTC, directly after the CC and 5 weeks later, patients were asked what they were most reluctant to undergo.

Table 1 Scales used by observer 1 to rate image quality (upper part) and scales used by the patients to rate experience and preference

\begin{tabular}{|c|c|}
\hline Observer 1: & Scale \\
\hline Image quality (patient, segment)* & $\begin{array}{l}\text { 1: poor, not diagnostic; } 2 \text { : moderate, diagnostic with limitations; } 3 \text { : good, diagnostic with minor } \\
\text { limitations; 4: excellent, no limitations }\end{array}$ \\
\hline Distension (segment) & $\begin{array}{l}\text { 1: collapsed; 2: poorly distended; } 3 \text { : only moderately distended but segment is distended over its } \\
\text { full length; 4: good; } 5 \text { : very good }\end{array}$ \\
\hline Homogeneity (segment) & 1: poor; $2:$ moderate; $3:$ good; $4:$ very good \\
\hline Presence of stool (segmemt) & $\begin{array}{l}\text { 1: large amount of stool, segment fully filled; } 2 \text { : moderate amount of stool, } \sim 50 \% \text { of lumen filled; } \\
\text { 3: small amount of stool; } 4 \text { : only contrast layer on the wall; } 5: \text { no stool at all }\end{array}$ \\
\hline \multicolumn{2}{|l|}{ Patients: } \\
\hline Most burdensome aspect & $\begin{array}{l}\text { CTC preparation: diet, lactulose, contrast agent } \\
\text { CTC: iv puncture, catheter placing, insufflation, breathholds, prone position } \\
\text { CC: iv puncture, moving of scope, air insufflation, monitoring after CC }\end{array}$ \\
\hline How burdensome/painful & Not, mild, moderate, severe, extreme \\
\hline Preference & Definitely CTC, probably CTC, possibly CTC, indifferent, possibly CC, probably CC, definitely CC \\
\hline Most reluctant factor & $\mathrm{CC}$, bowel preparation prior to the $\mathrm{CC}, \mathrm{CTC}$, the limited bowel preparation prior to the $\mathrm{CTC}$ \\
\hline
\end{tabular}

*The items were scored per patient and per segment. 
Statistical analysis

Differences in quality between CTC images of different segments were assessed using ordinal regression analysis. For this analysis we first determined the best segment and used this segment as reference segment. The regression coefficient of each segment estimates the change in the log transformed diagnostic odds ratio (DOR) compared to the reference segment. It can be interpreted, after antilogarithm transformation as relative diagnostic odds ratio (RDOR). A lower RDOR implies inferior image quality of the respective segment compared to the reference segment. Differences in polyp detection rates between CC and lower dose CTC were assessed with the McNemar test for paired proportions. The Wilcoxon signed rank test statistic was used to evaluate differences in patient experience between CTC and CC and to evaluate differences in preference between the questionnaire filled out directly after the procedures and 5 weeks later. The data were first dichotomized as preference for CTC versus preference for $\mathrm{CC}$. These differences were tested using the chi-square test statistic. All $P$-values $<0.05$ were considered to indicate statistical significance.

\section{Results}

Sixty-three eligible patients (53\%) gave written informed consent. Two patients were excluded. One patient was excluded since he did not undergo $\mathrm{CC}$ for unknown reasons. In another patient with a $20-\mathrm{mm}$ carcinoma opposite the ileocecal valve at CC, the CTC was rated as of no diagnostic value by both observers (parts of the large bowel not in the field of view, stool not tagged sufficiently, and breathing movement artifacts). Therefore, 61 patients were analyzed (Table 2); 51 of these 61 patients could be reviewed regarding dose reduction.

In five patients it was not possible to fully inspect the colon endoscopically. In one patient a $14-\mathrm{mm}$ polyp was seen at CTC in a segment not inspected at CC and confirmed at surgery (not included in the analysis). In two patients, repeat CC showed a $30-\mathrm{mm}$ polyp and a $30-\mathrm{mm}$ carcinoma (included in the analyses), both missed at the initial CC.

\section{Image quality}

Overall image quality was rated as excellent in 2 patients, good in 41 and moderate in 18 . One patient who received a score of poor/not diagnostic was excluded. Image quality was significantly lower (Fig. 1) in the cecum (both positions), sigmoid (prone position) and rectum (supine position). This was mainly due to inferior homogeneity in the cecum and rectum and inferior distension in the sigmoid and rectum.
Table 2 Baseline characteristics of the study population

\begin{tabular}{|c|c|}
\hline Included & 61 \\
\hline Male/female & $40 / 21$ \\
\hline Age in years: mean $\pm \mathrm{sd}^{\dagger}$ (range) & $\begin{array}{l}61 \pm 12 \\
(27-81)\end{array}$ \\
\hline \multicolumn{2}{|l|}{ Indication: } \\
\hline $\mathrm{H} / \mathrm{O}^{\dagger}$ colorectal polyps & 38 \\
\hline $\mathrm{H} / \mathrm{O}$ colorectal carcinoma & 9 \\
\hline $\mathrm{F} / \mathrm{H}^{\dagger}$ of colorectal polyps or cancer & 14 \\
\hline $\begin{array}{l}\text { Coexistent complains: Abdominal pain/hematochezia/ } \\
\text { altered bowel habits }\end{array}$ & $12 / 4 / 3$ \\
\hline \multicolumn{2}{|l|}{ Colonoscopy: number of polyps/patients with polyps: } \\
\hline Any size & $94 / 38$ \\
\hline$\geq 6 \mathrm{~mm}$ & $28 / 20$ \\
\hline$\geq 10 \mathrm{~mm}$ & $15 / 12$ \\
\hline$\geq 10 \mathrm{~mm}$ initial colonoscopy & $13 / 11$ \\
\hline Morphology of polyps $\geq 6 \mathrm{~mm}$ (sessile/stalked/flat/CRC) & $12 / 7 / 7 / 2$ \\
\hline Morphology of polyps $\geq 10 \mathrm{~mm}$ (sessile/stalked/flat/CRC) & $3 / 6 / 4 / 2$ \\
\hline $\begin{array}{l}\text { Colonoscopy: no. of patients receiving Sed+analg/sed/ } \\
\text { analg/none }\end{array}$ & $29 / 7 / 3 / 22$ \\
\hline Stool consistency prior to CTC (diarrhea/soft/normal) & $15 / 13 / 33$ \\
\hline Abdominal pain prior to CTC (major/minor) & $1 / 7$ \\
\hline Flatulence prior to CTC (major/minor) & $3 / 27$ \\
\hline Spasmolitycs during CTC (Buscopan/Glucagon/neither) & $47 / 12 / 2$ \\
\hline
\end{tabular}

Diagnostic value

Including the findings at repeat $\mathrm{CC}, 12$ patients had 15 polyps $\geq 10 \mathrm{~mm}$ (including 2 carcinomas of $35 \mathrm{~mm}$ and $30 \mathrm{~mm}$ ) while 20 patients had in total 28 polyps $\geq 6 \mathrm{~mm}$ (Fig. 2). Twenty-three of 61 patients did not have any polyps at colonoscopy. The initial CC detected 13 of the 15 large polyps (sensitivity $87 \%$ ). The per-patient sensitivity for the initial CC was $92 \%(11 / 12)$. The unblinded research fellow was able to match 13/15 (87\%) large polyps (in 10/12 patients: $83 \%$ ), while 2 large flat lesions were not visible in retrospect. For polyps $\geq 6 \mathrm{~mm}$ he matched $23 / 28$ (87\%) polyps (3 additional flat lesions not visible in a patient with already a large flat lesion) in $18 / 20(90 \%)$ patients. Observers 1 and 2 correctly identified 10/15 $(67 \%)$ and $9 / 15(60 \%)$ polyps $\geq 10 \mathrm{~mm}$, with respectively 5 and 8 false-positive lesions (Table 3). All but two were explained as stool.

\section{Polyp detection at lower dose-levels}

In 51 of 61 patients, we were able to simulate and reconstruct data at lower dose levels. In 10 of 61 patients 
this was not possible due to missing original raw data. Dose reduction down to $0.7 \mathrm{mSv}$ was not associated with significant changes in diagnostic value for patients with lesions $\geq 10 \mathrm{~mm}$ (Table 4, Figs. 3 and 4). Only focusing on the data of these 51 patients, reader 3 showed diagnostic values comparable to or even better than reviewer 1 and 2 : sensitivity for reviewer 1 and 2 both 5 out of 10 large polyps with respectively 5 and 8 false-positive lesions $\geq 10 \mathrm{~mm}$ and respectively 10 and 9 out of 20 polyps $\geq 6 \mathrm{~mm}$ with respectively 20 and 25 false-positives $\geq 6 \mathrm{~mm}$. Specificity for patients without lesions $\geq 6 \mathrm{~mm}$ was significantly lower $(\mathrm{P}=0.003)$ at $6 \mathrm{mAs}$ when compared to the original dose.

\section{Patient experience and preference}

The 6 questionnaires were filled out by respectively 58 (95\%), $61(100 \%), 61(100 \%), 56(92 \%), 57(93 \%)$ and 57 (93\%) patients. Two weeks prior to the CTC patients were most reluctant to undergo $\mathrm{CC}$, then the $\mathrm{CC}$ bowel preparation, thirdly the limited CTC bowel preparation. The CTC was feared least. After both procedures (fifth questionnaire), the order was the same. Five weeks later the bowel preparation prior to the $\mathrm{CC}$ was regarded to be the most burdensome, followed by the $\mathrm{CC}$, then the CTC preparation and the CTC. None of the three aspects of the bowel preparation for CTC (the diet, lactulose and contrast agent) was rated significantly worse than the others (Fig. 5). Patients rated the limited bowel preparation (prior to CTC) less burdensome than the bowel preparation prior to CC (Fig. 6, $P<0.001$ ). Patients also experienced more pain during CC than during CTC (Fig. $6, P<0.001$ ). The most burdening aspect of the CTC was insufflation of air (58\%). The most burdening aspect of $\mathrm{CC}$ was the movement of the scope (59\%). Directly after the CC (fifth questionnaire) $80 \%(43 / 54)$ of the patients preferred CTC for their next examination, $13 \%$ (7) preferred $\mathrm{CC}$ $(P<0.001)$ and $7 \%$ (4) were indifferent (Fig. 6). Five weeks after the procedures, $71 \%(39 / 55)$ preferred CTC, $13 \%$ (7) preferred CC $(P<0.001)$ and $18 \%(10)$ were indifferent. After 5 weeks there was no change $(P=0.12)$ in preference of CTC as the next screening test.

\section{Discussion}

This study demonstrates that CT colonography without cleansing is preferred to colonoscopy and shows moderate
Fig. 1 Figure showing RDOR with confidence intervals of all six segments of the colorectum in both prone and supine position regarding overall image quality, distension, presence of stool and homogeneity. All segments are compared to the best segment (DOR by definition 1). Confidence intervals not reaching 1 indicate significantly inferior results
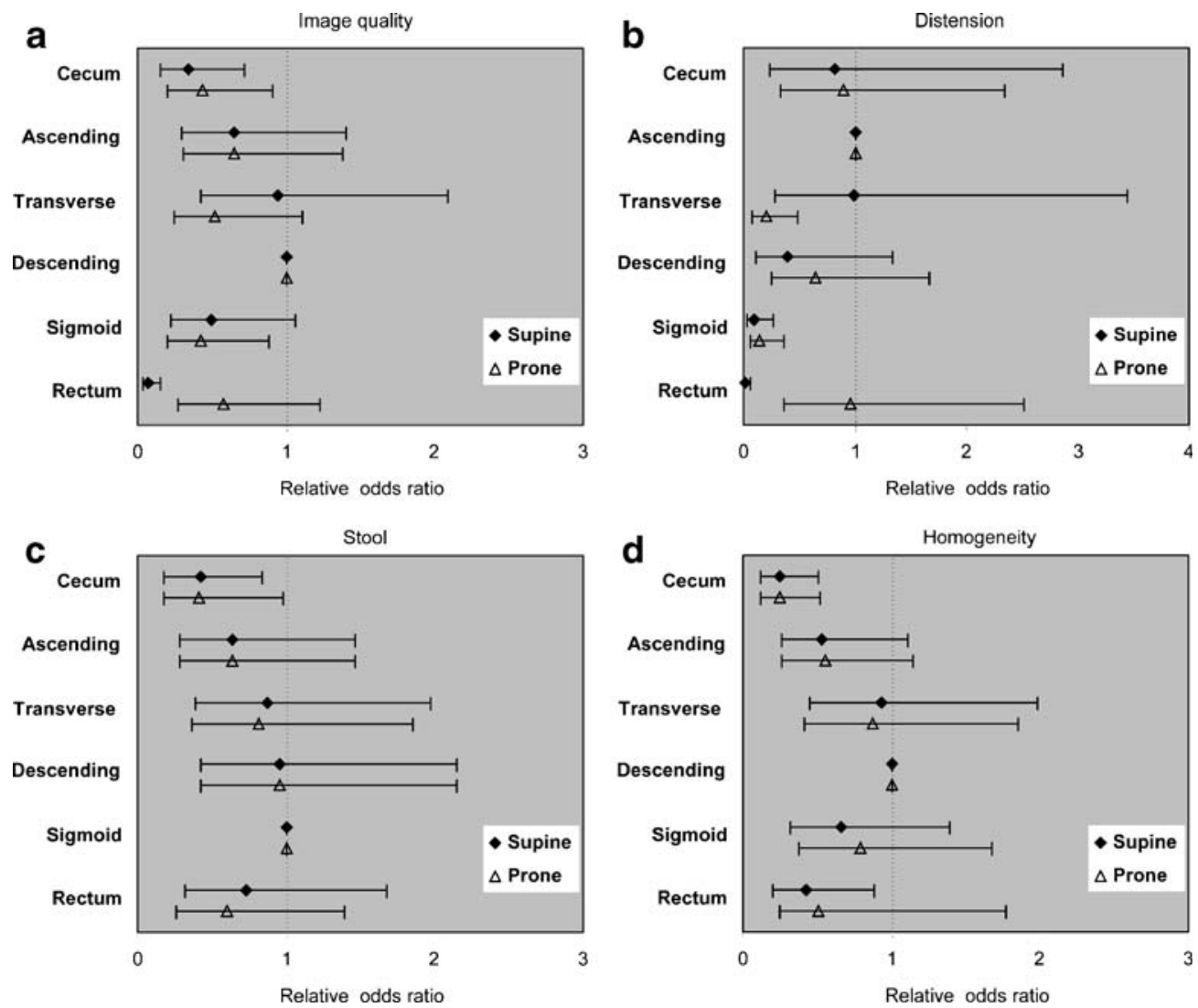
Fig. 2 A 76-year-old woman with a 7 -mm stalked polyp (arrow) submerged in a layer of tagged stool at CTC (original dose; $\mathbf{a}$ : supine position, $\mathbf{b}$ prone position) and at colonoscopy (c)
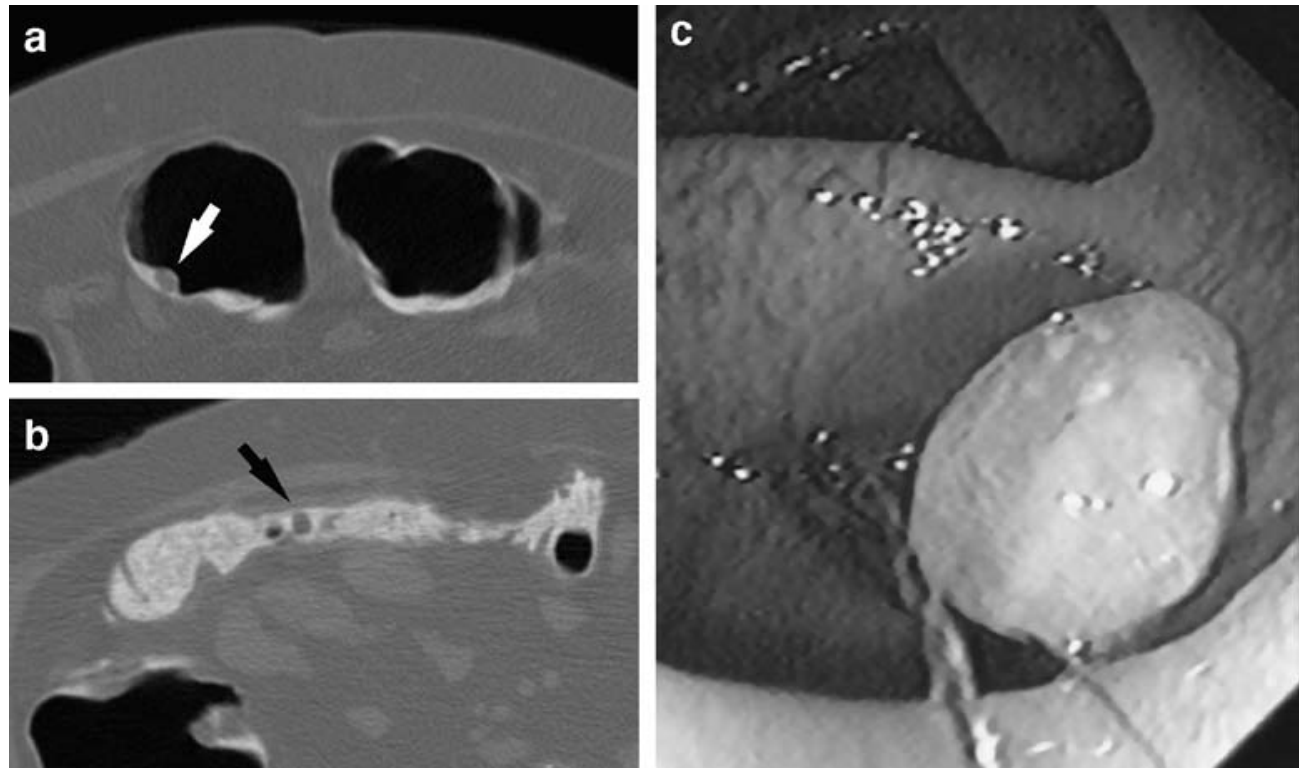

sensitivity (60-67\%) for polyps $\geq 10 \mathrm{~mm}$ without impaired diagnostic value at $\mathrm{mSv}$ levels as low as $0.7 \mathrm{mSv}$.

Image quality was good on average. Nevertheless, the cecum, sigmoid and rectum showed overall reduced image quality. Although this can be caused by the pelvis causing more noise, reduced imaged quality must probably be attributed to inferior homogeneity in the cecum and rectum and inferior distension in the sigmoid and rectum in the prone position. In contrast to the known problems in CTC with distension, which are solved by dual positioning, inferior homogeneity in the cecum and rectum are typical for the limited bowel preparation protocol. Insufficient homogeneity in the cecum is probably caused by the fact that patients ate food after the last amount of contrast agent was taken, resulting in inadequately tagged stool. The inhomogeneous stool in the rectum probably was caused by the fact that in patients with a long transit time stool was already shaped before the fecal tagging was started.

We assume that two adaptations are necessary to improve image quality. First, contrast must be taken as long as the patients are eating. Second, stool should be made softer, for example by replacing lactulose by a stronger osmotic laxative (e.g., low-dose magnesium salts), thereby also reducing the transit time and reducing the amount of non-tagged stool in the rectum. Although these adaptations increase the burden of the bowel preparation, they are slight and are required to improve image quality and thereby maybe the sensitivity and specificity.

Table 3 Performance characteristics per observer per size category

\begin{tabular}{lllll}
\hline Variable & \multicolumn{3}{l}{ Polyps $\geq 10 \mathrm{~mm}$} & \multicolumn{2}{l}{ Polyps $\geq 6 \mathrm{~mm}$} \\
\cline { 2 - 3 } & \multicolumn{2}{l}{ Observer: } & \multicolumn{1}{l}{ Observer: } \\
\cline { 2 - 3 } & 1 & 2 & 1 & \\
\hline Analysis according to polyp & $10 / 15(67 \%)$ & $9 / 15(60 \%)$ & $17 / 28(61 \%)$ & $15 / 28(54 \%)$ \\
Sensitivity & 5 & 8 & 20 & 28 \\
FP & $10 / 16(63 \%)$ & $9 / 17(53 \%)$ & $17 / 38(45 \%)$ & $15 / 43(35 \%)$ \\
PPV & & & & \\
Analysis according to patient & $8 / 12(67 \%)$ & $8 / 12(67 \%)$ & $13 / 20(65 \%)$ & $13 / 20(65 \%)$ \\
Sensitivity & $45 / 49(92 \%)$ & $41 / 49(84 \%)$ & $30 / 41(73 \%)$ & $25 / 41(73 \%)$ \\
Specificity & $8 / 12(67 \%)$ & $8 / 16(50 \%)$ & $13 / 24(54 \%)$ & $13 / 29(45 \%)$ \\
PPV & $45 / 49(92 \%)$ & $41 / 45(91 \%)$ & $30 / 37(81 \%)$ & $25 / 32(78 \%)$ \\
NPV & &
\end{tabular}

PPV: positive predictive value; NPV: negative predictive value; FP: false positives; CI: confidence interval 
Table 4 Performance characteristics of observer 3 per dose level

\begin{tabular}{|c|c|c|c|c|c|c|}
\hline \multirow[t]{3}{*}{ Variable } & \multicolumn{3}{|c|}{ Polyps $\geq 10 \mathrm{~mm}$} & \multicolumn{3}{|c|}{ Polyps $\geq 6 \mathrm{~mm}$} \\
\hline & \multicolumn{3}{|l|}{ Dose level } & \multicolumn{3}{|l|}{ Dose level } \\
\hline & Original & $2.3 \mathrm{mSv}$ & $0.7 \mathrm{mSv}$ & Original & $2.3 \mathrm{mSv}$ & $0.7 \mathrm{mSv}$ \\
\hline \multicolumn{7}{|c|}{ Analysis according to polyp } \\
\hline Sensitivity & $5 / 10(50 \%)$ & $7 / 10(70 \%)$ & $4 / 10(40 \%)$ & $11 / 20(55 \%)$ & $13 / 20(65 \%)$ & $10 / 20(50 \%)$ \\
\hline FP & 2 & 2 & 4 & 5 & 11 & 20 \\
\hline \multicolumn{7}{|c|}{ Analysis according to patient } \\
\hline Sensitivity & $5 / 9(56 \%)$ & $7 / 9(78 \%)$ & $4 / 9(44 \%)$ & $10 / 15(67 \%)$ & $12 / 15(60 \%)$ & $9 / 15(45 \%)$ \\
\hline Specificity & $40 / 42(95 \%)$ & $40 / 42(95 \%)$ & $39 / 42(93 \%)$ & $33 / 36(92 \%)$ & $26 / 36(72 \%)$ & $23 / 36^{\mathrm{SS}}(64 \%)$ \\
\hline
\end{tabular}

ss: statistically significant. FP: false positives

Statistical analysis (only performed on the per patient data) showed that only the specificity for patients without lesions $\geq 6 \mathrm{~mm}$ was significantly lower $(P=0.003)$ at $0.7 \mathrm{mSv}$ when compared to the original dose

Fig. 3 Figure showing a large 12-mm false-positive lesion (arrow) in the transverse colon at three different dose levels in a 65-year-old male patient (a: $0.7 \mathrm{mSv}, \mathbf{b}: 2.3 \mathrm{mSv}$, c: original). At lower dose levels it is more difficult to differentiate this lesion from a true-positive lesion (polyp) when fecal material is insufficiently tagged, this especially applied to smaller lesions. Well-tagged material is clearly differentiated from colon wall, even at $0.7 \mathrm{mSv}$ (arrowhead)
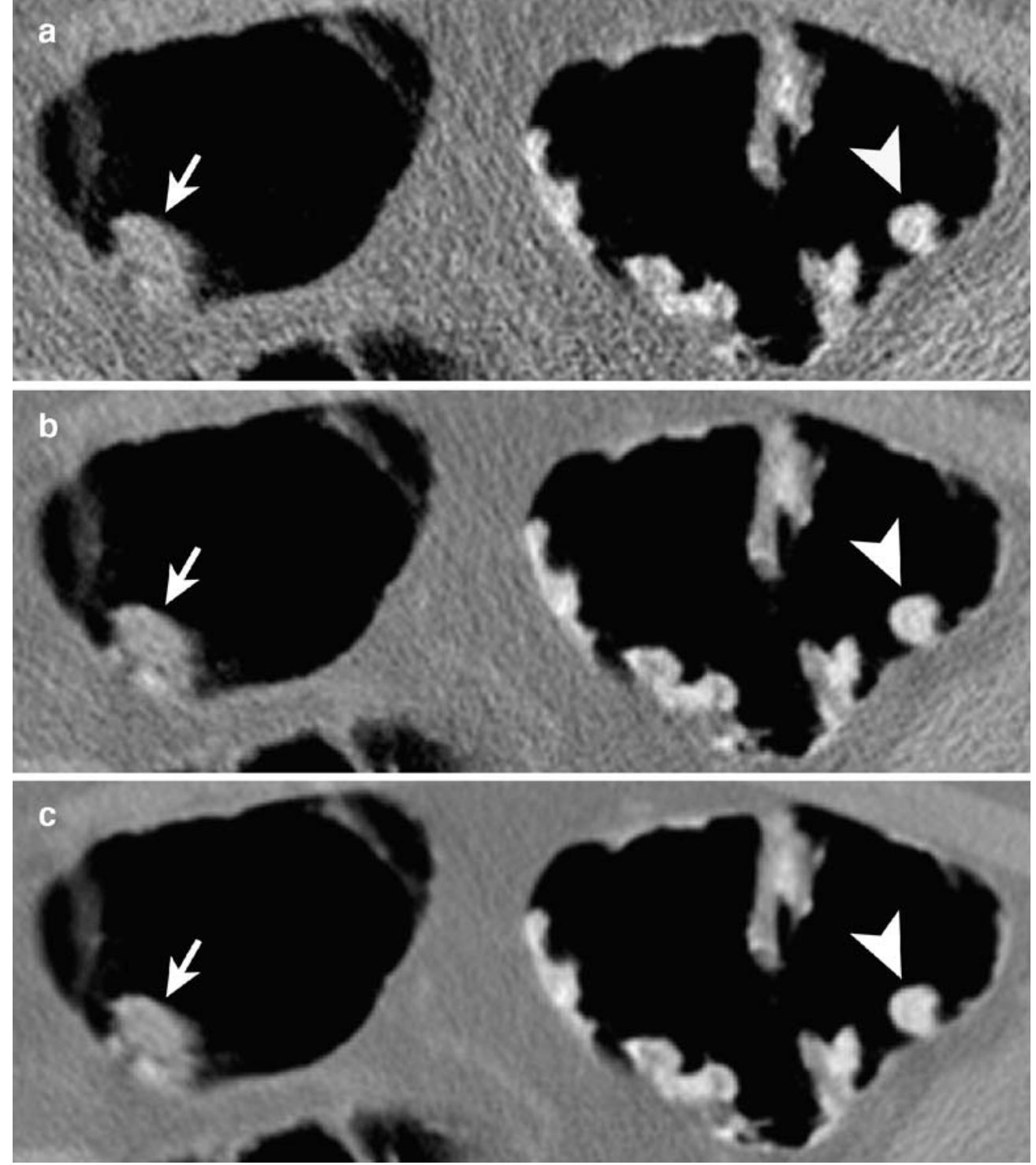
Fig. 4 Figure showing a large 10-mm stalked polyp (arrowhead) in the sigmoid at three different dose levels in a 57year-old male patient (a: $0.7 \mathrm{mSv}, \mathbf{b}: 2.3 \mathrm{mSv}$, c: original)
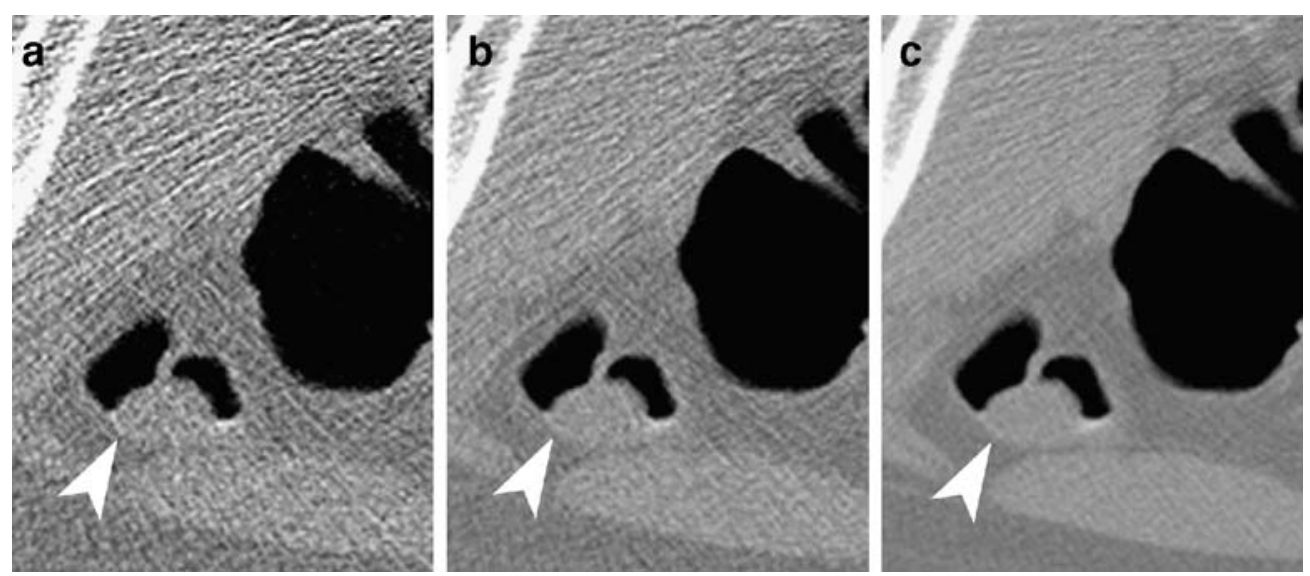

Our study showed an average sensitivity of $63 \%$ for large polyps (with a limited number of large false-positive lesions). This is lower than the $100 \%$ average sensitivity described by Iannaccone et al. [7] using a more or less comparable bowel preparation; no fiber-rich food and $200 \mathrm{ml}$ of $370 \mathrm{mg} / \mathrm{ml}$ iodinated contrast agent in $48 \mathrm{~h}$ (which is 6.3 times the amount given in our study), but no lactulose. In addition to the differences in bowel preparation, differences in experience of the readers or reader performance, difference in study groups (polyp prevalence and spectrum) might explain these discrepant results. A recent study [20] has shown inferior results regarding diagnostic value of CTC in populations at increased risk, as is used in the current study, possibly due to a relatively high number of hard-to-see polyps. When comparing our study with three large studies on CTC with extensive bowel preparation [21-23] (showing per polyp sensitivities of respectively $52 \%, 32-73 \%$ and $53 \%$ for polyps $\geq 10 \mathrm{~mm}$ ), our results are comparable or slightly better.

Since two of five (observer 1) and two of six (observer 2) missed polyps were not seen in retrospect by the unblinded observer, the problem of missing large polyps can be regarded as predominantly an interpretation problem rather than a visualization problem. Future developments, such as better homogeneity, better distension, better learning curve, intuitive display modes, electronic cleansing and computer-aided detection can help in reducing the number of missed polyps.

Sensitivity and specificity were impaired at lower dose levels for patients with lesions $\geq 10 \mathrm{~mm}$. This is especially of interest in screening protocols. Regarding lesions $\geq 6 \mathrm{~mm}$, specificity was significantly lower at the simulated $0.7 \mathrm{mSv}$ low-dose scans. Increased noise levels made it impossible to see the tiny air bubbles inside stool. These results may seem to be in contrast with those in an earlier report on low radiation dose CTC [13] showing fewer false-positive lesions. However, these studies in patients with extensively cleansed colons used a three-dimensional display mode and filters to smooth the bowel wall. By using these smoothing filters, small artifacts and small amounts of residual stool were masked when evaluating the colon three dimensionally. Making stool softer and scanning with thinner slices possibly allows for better visualization of the air bubbles, thereby reducing the number of false positives.

Patient acceptance was found to be very good in the current study. Patient preference was convincingly in favor of CTC; $71 \%$ of patients preferred CTC with limited bowel preparation to CC for their next examination. Other studies have shown discrepant results on patient acceptance of CTC versus CC, some favoring CTC [24-27], others CC $[28,29]$. In a study where patients first underwent extensive cleansing and consecutively CTC and CC [24] fewer patients $(71 \%$ directly after the CC) favored CTC when compared to our study ( $80 \%$ directly after CC). This difference cannot be attributed to the bowel preparation because of a different study setup.

Several potential limitations must be considered. The number of patients included is relatively low, especially for determining the detection parameters at the 2.3 and $0.7 \mathrm{mSv}$ levels.

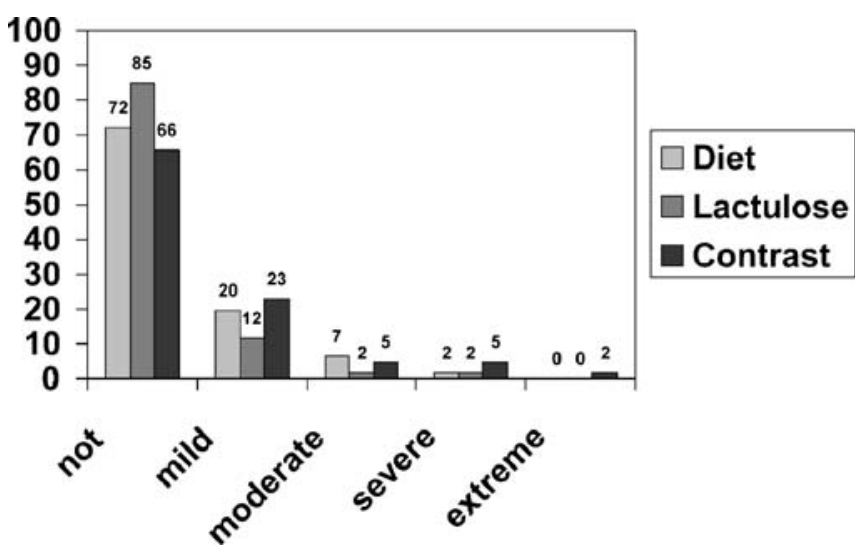

Fig. 5 Graph showing how patients rated the three different components of CTC with limited bowel preparation. How burdensome were the diet, lactulose and the contrast agent? 
Fig. 6 Graphs show patients' experience of the bowel preparation (upper left) and the CTC examination (upper right) and patient preference for one of the two modalities (CTC with limited bowel preparation versus CTC with standard bowel preparation, lower). How burdensome was the limited bowel preparation prior to CTC (grey) as compared to cleansing prior to CC (black)? How burdensome were the CTC (grey) and $\mathrm{CC}$ (black) examinations (upper right graphs)? What did participants prefer for their next examination (lower graph) directly after both examinations and in the questionnaire sent at home 5 weeks later?
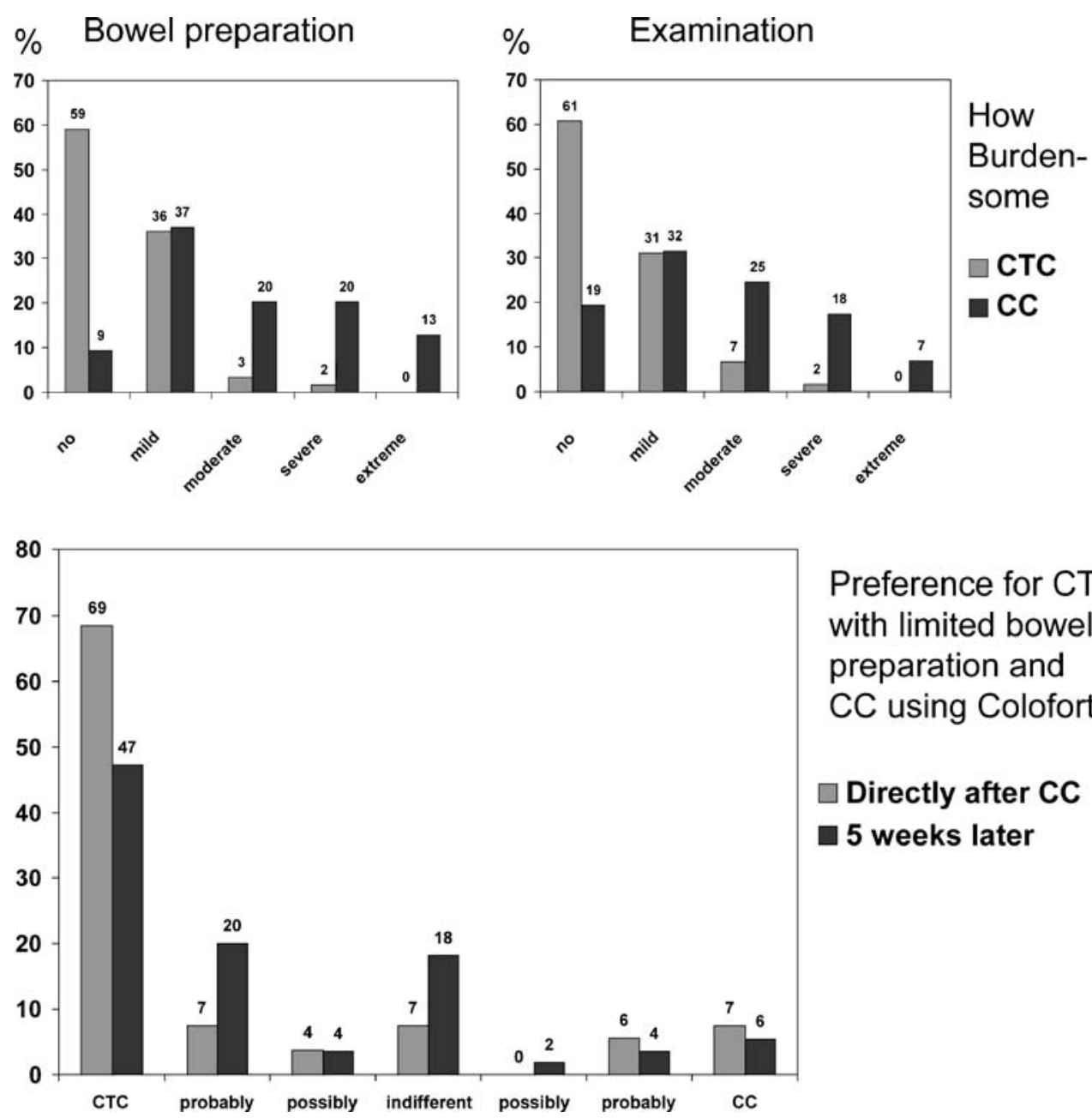

Preference for CTC with limited bowel preparation and CC using Colofort

$\square$ Directly after CC 5 weeks later
In the current study no segmental unblinding during $\mathrm{CC}$ was performed. Although repeat $\mathrm{CC}$ showed that two large false-positive lesions were missed at the initial CC, segmental unblinding has the advantage of evaluating all false positives.

Since no electronic cleansing was used and many polyps were submerged, 3D evaluation of these lesions was not of additive value. However, 3D evaluation with electronic cleansing might have given better results, especially since most missed polyps were visible in retrospect.

Although the two readers that had no previous experience in CTC underwent a learning curve of 50 patients, some studies have shown that this may not be sufficient for optimal polyp detection [30, 31]. For CTC using limited bowel preparation, the learning curve is possibly even longer.
When filling out the questionnaires, sensitivity for $\mathrm{CC}$ and $\mathrm{CTC}$ were assumed equal. If patients knew that the sensitivity of CTC was lower than for CC, this most likely would have influenced the preference for CTC negatively.

In conclusion, these results show that $\mathrm{CTC}$ with the limited bowel preparation protocol used in this study is feasible, even when using doses as low as $0.7 \mathrm{mSv}$ levels. Although sensitivity was not as high as previously reported, this is most likely not due to the limited bowel preparation, but to interpretation problems. Technical developments will probably increase the sensitivity, while minor adjustments in bowel preparation may reduce the number of false positives, especially when using low-dose protocols. Since patient acceptance was very good, this technique can be regarded as promising in screening patients of populations with a low prevalence of polyps. 


\section{References}

1. Fenlon HM, Nunes DP, Schroy PC 3rd, Barish MA, Clarke PD, Ferrucci JT (1999) A comparison of virtual and conventional colonoscopy for the detection of colorectal polyps. N Engl J Med 341:1496-1503

2. Yee J, Akerkar GA, Hung RK, Steinauer-Gebauer AM, Wall SD, McQuaid KR (2001) Colorectal neoplasia: performance characteristics of CT colonography for detection in 300 patients. Radiology 219:685-692

3. Pineau BC, Paskett ED, Chen GJ, Espeland MA, Phillips K, Han JP, Mikulaninec C, Vining DJ (2003) Virtual colonoscopy using oral contrast compared with colonoscopy for the detection of patients with colorectal polyps. Gastroenterology 125:304-310. DOI 10.1016/S0016-5085(03)00885-0

4. Fletcher JG, Johnson CD, Welch TJ, MacCarty RL, Ahlquist DA, Reed JE, Harmsen WS, Wilson LA (2000) Optimization of CT colonography technique: Prospective trial in 180 patients. Radiology 216:704-711

5. Pickhardt PJ, Choi JR, Hwang I, Butler JA, Puckett ML, Hildebrandt HA, Wong RK, Nugent PA, Mysliwiec PA, Schindler WR (2003) Computed tomographic virtual colonoscopy to screen for colorectal neoplasia in asymptomatic adults. N Engl J Med 349:2191-2200

6. Van Gelder RE, Nio CY, Florie J, Bartelsman JF, Snel P, De Jager SW, Van Deventer SJ, Lameris JS, Bossuyt PM, Stoker J (2004) Computed tomographic colonography compared with colonoscopy in patients at increased risk for colorectal cancer. Gastroenterology 127:41-48. DOI 10.1053/j.gastro.2004.03.055

7. Iannaccone R, Laghi A, Catalano C, Mangiapane F, Lamazza A, Schillaci A, Sinibaldi G, Murakami T, Sammartino P, Hori M, Piacentini F, Nofroni I, Stipa V, Passariello R (2004) Computed tomographic colonography without cathartic preparation for the detection of colorectal polyps. Gastroenterology 127:1300-1311. DOI 10.1053/ j.gastro.2004.08.025

8. Lefere P, Gryspeerdt S, Marrannes J, Baekelandt M, Van Holsbeeck B (2005) CT colonography after fecal tagging with a reduced cathartic cleansing and a reduced volume of barium. AJR Am J Roentgenol 184:1836-1842
9. Zalis ME, Perumpillichira JJ, Magee C, Kohlberg G, Hahn PF (2006) Taggingbased, electronically cleansed CT colonography: evaluation of patient comfort and image readability. Radiology 239:149-159. DOI 10.1148/ radiol.2383041308

10. Bielen D, Thomeer M, Vanbeckevoort D, Kiss G, Maes F, Marchal G, Rutgeerts P (2003) Dry preparation for virtual CT colonography with fecal tagging using water-soluble contrast medium: initial results. Eur Radiol 13:453-458. DOI 10.1007/s00330-0021755-X

11. Lefere PA, Gryspeerdt SS, Dewyspelaere J, Baekelandt M, Van Holsbeeck BG (2002) Dietary fecal tagging as a cleansing method before CT colonography: initial results polyp detection and patient acceptance. Radiology 224:393-403. DOI 10.1148/ radiol.2241011222

12. Callstrom MR, Johnson CD, Fletcher JG, Reed JE, Ahlquist DA, Harmsen WS, Tait K, Wilson LA, Corcoran KE (2001) CT colonography without cathartic preparation: feasibility study. Radiology 219:693-698

13. van Gelder RE, Venema HW, Florie J, Nio CY, Serlie IW, Schutter MP, van Rijn JC, Vos FM, Glas AS, Bossuyt PM, Bartelsman JF, Lameris JS, Stoker J (2004) CT colonography: feasibility of substantial dose reduction-comparison of medium to very low doses in identical patients. Radiology 232:611620. DOI 10.1148/radiol.2322031069

14. van Gelder RE, Venema HW, Serlie IW, Nio CY, Determann RM, Tipker CA, Vos FM, Glas AS, Bartelsman JF, Bossuyt PM, Lameris JS, Stoker J (2002) CT colonography at different radiation dose levels: feasibility of dose reduction. Radiology 224:25-33. DOI 10.1148/radiol.2241011126

15. Anupindi S, Perumpillichira J, Jaramillo D, Zalis ME, Israel EJ (2005) Low-dose CT colonography in children: initial experience, technical feasibility, and utility. Pediatr Radiol 35:518-524. DOI 10.1007/s00247-0041394-2

16. Winawer S, Fletcher R, Rex D, Bond J, Burt R, Ferrucci J, Ganiats T, Levin T, Woolf S, Johnson D, Kirk L, Litin S, Simmang C; Gastrointestinal Consortium Panel (2003) Colorectal cancer screening and surveillance: clinical guidelines and rationale-Update based on new evidence. Gastroenterology 124:544-560. DOI 10.1053/ gast.2003.50044
17. Rembacken BJ, Fujii T, Cairns A, Dixon MF, Yoshida S, Chalmers DM, Axon AT (2000) Flat and depressed colonic neoplasms: a prospective study of 1000 colonoscopies in the UK. Lancet 355:1211-1214

18. Venema HW (2002) Simulation of CTscans with a very low dose as a research tool for ALARA studies (abstr). Radiology 225(P):592-593

19. Mayo JR, Whittall KP, Leung AN, Hartman TE, Park CS, Primack SL, Chambers GK, Limkeman MK, Toth TL, Fox SH (1997) Simulated dose reduction in conventional chest $\mathrm{CT}$ : validation study. Radiology 202: 453-457

20. MacCarty RL, Johnson CD, Fletcher JG, Wilson LA (2006) Occult colorectal polyps on CT colonography: implications for surveillance. AJR Am J Roentgenol 186:1380-1383. DOI 10.2214/AJR.05.0031

21. Cotton PB, Durkalski VL, Pineau BC, Palesch YY, Mauldin PD, Hoffman B, Vining DJ, Small WC, Affronti J, Rex D, Kopecky KK, Ackerman S, Burdick JS, Brewington C, Turner MA, Zfass A, Wright AR, Iyer RB, Lynch P, Sivak MV, Butler H (2004) Computed tomographic colonography (virtual colonoscopy): a multicenter comparison with standard colonoscopy for detection of colorectal neoplasia. JAMA 291: 1713-1719

22. Johnson CD, Harmsen WS, Wilson LA, MacCarty RL, Welch TJ, Ilstrup DM, Ahlquist DA (2003) Prospective blinded evaluation of computed tomographic colonography for screen detection of colorectal polyps. Gastroenterology 125:311-319. DOI 10.1016/s0016-5085(03)00894-1

23. Rockey DC, Paulson E, Niedzwiecki D, Davis W, Bosworth HB, Sanders L, Yee J, Henderson J, Hatten P, Burdick S, Sanyal A, Rubin DT, Sterling M, Akerkar G, Bhutani MS, Binmoeller K, Garvie J, Bini EJ, Mcuaid K, Foster WL, Thompson WM, Dachman A, Halvorsen R (2005) Analysis of air contrast barium enema, computed tomographic colonography, and colonoscopy: prospective comparison. Lancet 365:305-311 
24. van Gelder RE, Birnie E, Florie J, Schutter MP, Bonsel GJ, Stoker J (2003) Patient experience and preference of CT colonography and conventional colonoscopy: a five-week follow-up study. Radiology 229:328337. DOI 10.1148/radiol.2331031208

25. Svensson MH, Svensson E, Lasson A, Hellstrom M (2002) Patient acceptance of CT colonography and conventional colonoscopy: prospective comparative study in patients with or suspected of having colorectal disease. Radiology 222:337-345. DOI 10.1148/ radiol.2222010669
26. Gluecker TM, Johnson CD, Harmsen WS, Offord KP, Harris AM, Wilson LA, Ahlquist DA (2003) Colorectal cancer screening with CT colonography, colonoscopy, and double-contrast barium enema examination: prospective assessment of patient perceptions and preferences. Radiology 227:378 384. DOI 10.1148/radiol.2272020293

27. Thomeer M, Bielen D, Vanbeckevoort D, Dymarkowski S, Gevers A, Rutgeerts P, Hiele M, Van Cutsem E, Marchal G (2002) Patient acceptance for CT colonography: what is the real issue? Eur Radiol 12:1410-1415. DOI 10.1007/ s003300101082

28. Akerkar GA, Yee J, Hung R, McQuaid K (2001) Patient experience and preferences toward colon cancer screening: a comparison of virtual colonoscopy and conventional colonoscopy. Gastrointest Endosc 54:310-315. DOI 10.1067/mge.2001.117695
29. Forbes GM, Mendelson RM (2000) Patient acceptance of virtual colonoscopy. Endoscopy 32:274-275

30. Slater A, Taylor SA, Tam E, Gartner L, Scarth J, Peiris C, Gupta A, Marshall M, Burling D, Halligan S. (2006) Reader error during CT colonography: causes and implications for training. European Radiology 16:2275-2283. DOI 10.1007/s00330-006-0299-x

31. Taylor SA, Halligan S, Burling D, Morley S, Bassett P, Atkin W, Bartram CI (2004) CT colonography: effect of experience and training on reader performance. Eur Radiol 14:1025-33. DOI 10.1007/s00330-004-2262-z 